Georgia State University

ScholarWorks @ Georgia State University

\title{
Factors Affecting Burden of South Koreans Providing Care to Disabled Older Family Members
}

\author{
Minhong Lee \\ Eunkyong Yoon \\ Nancy P. Kropf \\ Georgia State University, nkropf@gsu.edu
}

Follow this and additional works at: https://scholarworks.gsu.edu/ssw_facpub

Part of the Social Work Commons

\section{Recommended Citation}

Lee, M., Yoon, E., \& Kropf, N. (2007). Factors Affecting Burden of South Koreans Providing Care to Disabled Older Family Members. International Journal of Aging and Human Development, 64(3), 245-262. DOI: 10.2190/C4U5-078N-R83L-P1MN

This Article is brought to you for free and open access by the School of Social Work at ScholarWorks @ Georgia State University. It has been accepted for inclusion in SW Publications by an authorized administrator of ScholarWorks @ Georgia State University. For more information, please contact scholarworks@gsu.edu. 


\title{
FACTORS AFFECTING BURDEN OF SOUTH KOREANS PROVIDING CARE TO DISABLED OLDER FAMILY MEMBERS
}

MINHONG LEE, PH.D.

Dong-Eui University

EUNKYUNG YOON, PH.D.

Jackson State University

NANCY P. KROPF, PH.D.

Georgia State University

\begin{abstract}
This study examined the determinants of caregiving burden among South Koreans who care for their disabled older family members. A sample of 1,000 primary caregivers taken from the Comprehensive Study for Elderly Welfare Policy in Seoul, South Korea was analyzed. Independent variables included the demographic characteristics of caregivers and care recipients, the severity of cognitive impairment among care recipients, care recipients' functional abilities, financial adequacy and caregivers' degree of social support. Hierarchical regression was used to predict the levels of caregivers' burden. Similar to western care providers, South Korean caregivers who were in poor health and who had little informal social support, inadequate financial resources and more weekly caregiving hours were more likely to experience intense caregiving burden. Burden was also positively related to the functional and cognitive disabilities of care recipients. The results of this study indicate that certain aspects of caregiving are unique to South Koreans. Daughters-in-law were the most common caregiver within the sample which indicates that South Korean eldercare is non-consanguineous. Identifying predictors of South Korean caregivers' burden promotes a more comprehensive understanding of cultural experiences in caring for older adults.
\end{abstract}




\section{BACKGROUND}

As an increase in the population of elderly people is a worldwide trend, care providers must engage in a great deal of discussion about how best to care for those elders with mental and/or physical disabilities (e.g., Huang, Shyu, Chen, Chen \& Lin, 2003). This issue is of particular concern in South Korea, because the number of South Korean elders continues to increase faster than in many other nations. The Korea National Statistical Office (KNSO) has reported that Koreans age 65 and older comprised $7.2 \%$ of the general population in 2000, a percentage that will increase to $23.1 \%$ by 2030 (KNSO, 2000a).

Despite the rapidly growing demands, formal social services are not likely to meet the immediate needs of caregivers who care for older family members with mental and/or physical impairment (Chee \& Levkoff, 2001). Day care, in-home services, short-term respite programs and institutional long-term care programs are extremely limited in Korea. Family members therefore take upon themselves the considerable responsibilities and stress associated with providing adequate care and supervision for their older relatives. For example, a recent survey revealed that only $3.6 \%$ of primary family caregivers use in-home services (Kim, 2003). In addition, a national representative study reported that approximately $0.3 \%$ of older adults in Korea reside in long-term care facilities (Korea Institute for Health and Social Affairs (KIHASA), 1998).

Cultural norms in South Korea affect caregiving burden as traditional factors still influence family roles for the care of dependent elderly. Most Koreans believe that elderly parents should be cared for by their adult children and many families live within intergenerational households (Levande, Herrick, \& Sung, 2000; Sung, 1991). For example, over $66 \%$ of older Koreans responded that adult children should have primary responsibility for caring their parents, and about $60 \%$ of family caregivers for older parents responded that elderly parents should be cared for by them (Kim, 2003). The KNSO (2000b) reported that $55.1 \%$ of persons age 65 and older still live with their children. A recent nationwide research has shown that $55.3 \%$ of physically and/or mentally impaired elders are primarily cared for by their adult children. By far, women surpassed men as caregivers with daughters-in-law comprising $35.1 \%$ of these care providers, and daughters adding an additional $13.5 \%$. Sons only accounted for a small (6.7\%) percentage of care providers (KIHASA, 2001).

The long-standing tradition in Korea has emphasized family harmony and filial piety for parents (Chee, 2000). The cultural expectation that the eldest son and his spouse should be responsible for his parents' care is still widely held in South Korea (Levande et al., 2000). Because of the paternalism espoused by the Confucian values of the past, daughters-in-law have been expected to adhere to social norms and to play pivotal roles in providing care for parents-in-law with disabilities (Kim, 2001; Knight, Robinson, Flynn Longmire, Chun, Nakao, \& Kim, 2002). 
These cultural characteristics in Korea have been an important factor in shaping gender differences related to caregiving tasks. The distinctive gender role for married men is to work outside the home to pay for living expenses, while wives have primary responsibility to take care of household affairs. Although men assume the financial responsibilities, they usually do not care for their mentally and physically impaired parents (Youn \& Song, 1992). This gendered role division leaves daughters-in-law to provide practically all physical care for their in-laws (Choi, 1993). Non-adherence to this cultural norm by a daughter-in-law may yield social criticism and familial conflict. Kim (2001) reported that daughters-in-law often perceived caregiving as very burdensome, due to cultural and social norms that forced them to accept their caregiving roles. Moreover, their motivation for caregiving usually comes from spousal obligation rather than voluntary affection for parent-in-laws (Knight et al., 2002). Many Korean studies indicated that these societal and familial obligations have tended to trigger Korean daughters-in-law to experience greater burden in the long-term care process (e.g., Lee, 2002).

However, dramatic social changes have come with modernization in Korea which greatly impacts the lives of families. Women increasingly participate in the paid work force, and multigenerational households, as well as family size in general, are gradually decreasing (Chee, 2000; Kim, 2001). Accordingly, women who are still pressed to care for the elderly tend to experience role conflicts between their traditional expectations and current opportunities and values. As middle-aged women, daughters-in-law hold various roles as parent, spouse and/or employee, which results in a degree of overload and exacerbates the perception of caregiving burden.

In summary, demographic trends among South Korean elders, inadequate social services and long-term care options, and cultural norms combine to make the issue of caregiving burden a phenomenon that demands societal attention. Most of the research on caregiving has been conducted in western countries and currently limited empirical research exists for large samples of South Korean families (Kim, Shin, Jeong, Gormley, \& Yoon, 2002). This study will identify significant factors related to caregiving burden among South Koreans who care for their disabled older family members.

\section{LITERATURE REVIEW}

Caregiver burden is commonly identified as a state resulting from the necessary care of an impaired older adult that threatens either the physical or psychological well-being of the caregiver (e.g., Zarit, Reever, \& Bach, 1980; Zarit, Todd, \& Zarit, 1986). Caregivers must deal with responsibilities of looking after a loved one and the emotional loss resulting from the care recipient's deterioration. In one study, for example, $44 \%$ of caregivers reported that their caregiving activities caused physical strains, and one-quarter reported that caregiving was emotionally 
stressful (Ory, Hoffman, Yee, Tennstedt, \& Schulz, 1999). The provision of care for an older person with limited functional abilities can have a number of harmful outcomes including less time for work and leisure, loss of privacy, constricted social networks, deteriorating relationships with the care recipient and other family members, stress, anxiety, depression, and even a possible deterioration of the caregiver's physical health (Aneshensel, Pearlin, Mullan, Zarit, \& Whitlatch, 1995; Neal, Chapman, Ingersol-Dayton, \& Emlen, 1993; Ory et al., 1999).

A number of studies have addressed the research question about the specific factors that lead to caregiving burden and stress. Within the caregiving dyad, burden is related to characteristics of both the caregiver and care recipient. In addition, the nature of the caregiving role, such as tasks and demands, also influence perceived burden. However, mitigating factors buffer the impact of burden such as resources and social support. Within the existing literature on caregiving, numerous studies have included these variables in research on caregiving burden (Kramer \& Kipnis, 1995; Miller, Townsend, Carpenter, Montgomery, Stull \& Young, 2001; Monahan \& Hooker, 1995).

Past research has shown that the demographic characteristics of caregivers influence perceptions of burden. Such characteristics as age, gender, education, marital status, income level, and relationship to and/or residence with the care recipient have been generally identified as significant predictors both in Western and Asian countries (e.g., Cantor, 1983; Chee \& Levkoff, 2001; Hughes, Giobbie-Hurder, Weaver, Kubal, \& Henderson, 1999; Kim \& Lee, 2003; Yoon, 2003). For example, female caregivers and older caregivers have association with a higher level of caregiving burden. In addition, family caregivers with less educational attainment, lower income and living together with care recipients were more likely to be highly burdened (Choi, 1993; Hughes et al., 1999; Miller et al., 2001). However, while daughters-in-law were more likely to have a higher level of burden in South Korea (Kim, 2001; Lee, 2002), the spouses of impaired elders in the USA experienced a higher degree of burden (Franks \& Stephens, 1996; Miller \& Guo, 2000; Monahan \& Hooker, 1995).

The nature of the caregiving role, including the associated tasks and demands, is also related to perceived burden (Barusch \& Spaid, 1989; Hannappel, Calsyn, \& Allen, 1993; Stull, Kosloski, \& Kercher, 1994). Several studies in South Korea have reported correlations between the care recipients's level of impairment, including functional and cognitive disabilities, and caregiving burden (Kim \& Lee, 2003; Lee, 2002; Yoon, 2003). Yoon (2003) analyzed 311 South Korean caregivers who provided care to a physically and/or cognitively impaired elderly family member, and found that the amount of caregiver burden was significantly related to the levels of functional and cognitive impairments present. Additionally, Choi (1993) reported greater time commitments to tasks of care provision were positively related to the burden reported by Korean caregivers. 
The ability of the caregiver to assume care demands has also been studied. Research has consistently shown that health status and the responsibility for additional dependents other than the elder care recipient, were significantly related to caregiver burden (Biegel \& Schulz, 1999; Bullock, Crawford \& Tennstedt, 2003; Burns \& Rabins, 2000; Call, Finch, Huck, \& Kane, 1999; Pratt, Schmall, Wright, \& Cleland, 1985; Thomas et al., 2002). A Korean study also reached the similar conclusion that family caregivers who were less capable, due to their own health or rival responsibilities, report higher levels of burden (Choi, 1993).

Research on social support has also investigated how both formal and informal support impacts caregiver burden. A consistent finding is that support, whether formal or informal, attenuates burden. Caregivers who use formal services, such as in-home nursing and respite care report lower stress levels (Miller et al., 2001; Monahan \& Hooker, 1995). In addition, a lack of social support generally increases role-related stress for care providers. Caregivers who report little support from family members other than the care recipient have reported more intense burden (Clipp \& George, 1990; Franks \& Stephens, 1996; Kim 2001; Kim \& Lee, 2003; Yoon, 2003).

In summary, previous studies have showed that socioeconomic status, the degree of the care recipient's impairment and the use of social support are associated with levels of caregiving burden. Although previous empirical studies have included predictors of perceived eldercare burden among South Koreans, these had relatively small samples and did not include both caregiving stress and mediating variables. This study sheds further light on the relationship between these variables with a large number of South Koreans caring for their elders with disabilities. Based upon a theoretical perspective that posits caregiving as a stressor within the family system (Kramer \& Kipnis, 1995; Pearlin, Mullan, Semple, \& Skaff, 1990), the following model has been constructed (Figure 1). Using this model as the conceptual framework, one research question is the basis for the current study, which is, "Within a sample of South Korean caregivers, what caregiver, care recipient, and resource variables best explain the level of caregiving burden?" Findings from the current study provide a basis for a richer understanding of care provision in South Korea.

\section{RESEARCH METHODS}

\section{Sample}

The data used in this study was drawn from the Comprehensive Study for the Elderly Welfare Policy in Seoul (Kim, 2003). Two non-probability sampling methods were employed to recruit 1,000 participants in this survey. A total of 2,318 records of older adults who had previously used or have used community adult day care centers or community nursing centers located in Seoul were obtained from the Seoul Metropolitan City's Mayor's Office, Welfare \& 
250 / LEE, YOON AND KROPF

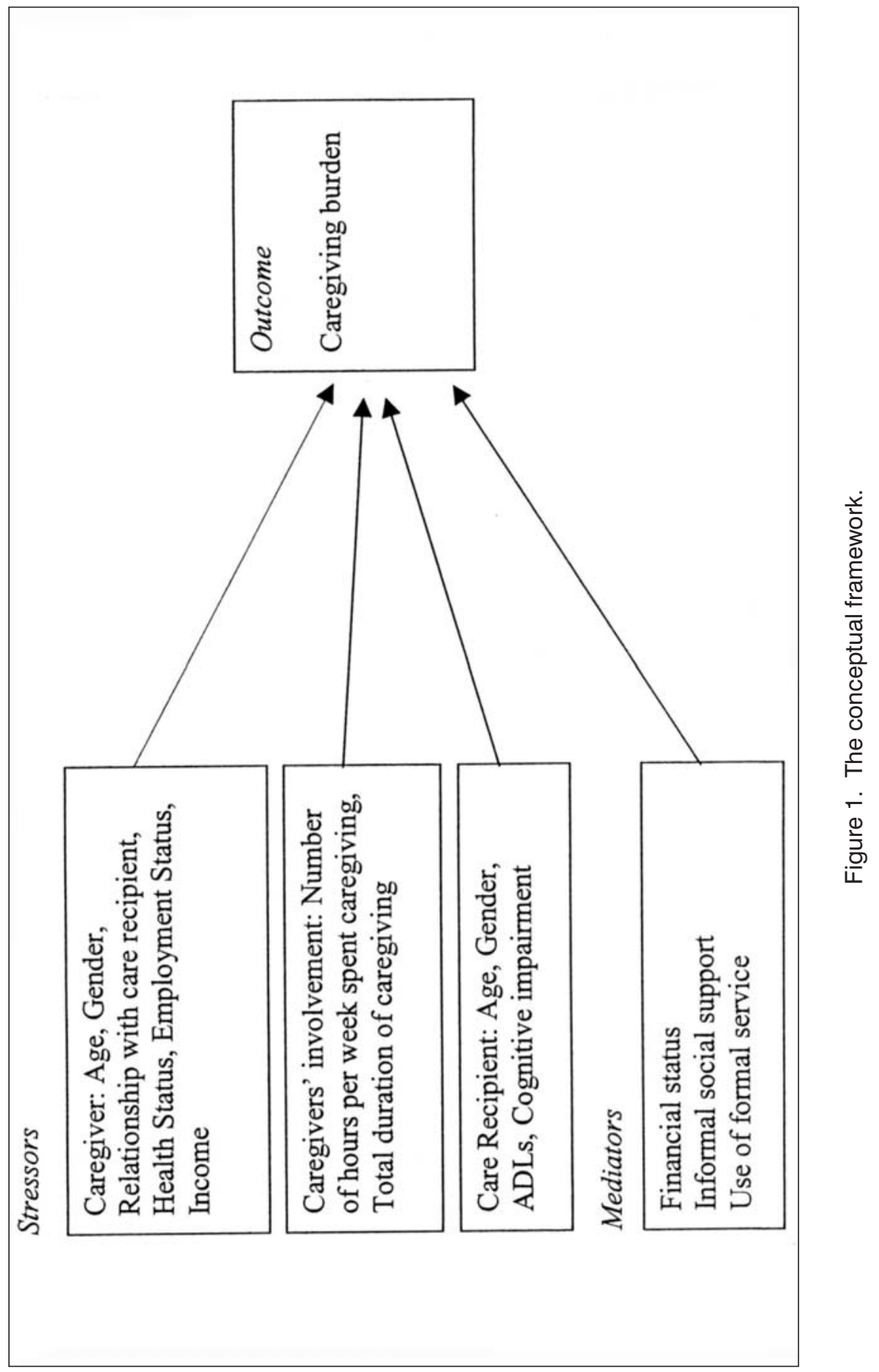


Women's Bureau. Initially, potential study participants were screened over the phone, and a total of 463 caregivers consented to participate. In an effort to increase the sample size, 40 trained middle-aged female interviewers were dispatched to 20 districts ("Gu"s) to identify eligible candidates meeting the criteria for this study. This profile of interviewer was hired since most caregivers are also middle-aged females. The expectation was that the caregivers, who are often reluctant to reveal their family problems or conflicts to other people, would be more likely to respond to an interviewer who shared similar demographic characteristics. This effort provided an additional yield of 537 primary family caregivers. The total sample size of the study was 1000 caregivers, all of whom were 21 years of age or older, with overall response rate of $45 \%$. The study was approved by Institutional Review Board (IRB) at the researchers' current university.

\section{Procedure}

All participants were questioned about their personal health, use of formal services, relationship with the elder, perceived caregiving burden and economic status. Interviews took place in the caregiver's home or in another mutually acceptable location. Due to current literacy levels among older South Koreans, interviewers read aloud the questions to participants.

\section{Measures}

\section{Caregivers' Characteristics}

Caregivers' characteristics were measured with several items. These items provided information about the caregiver's relationship with the care recipient, the caregiver's current physical health, employment status, residential arrangements, the number of hours per week spent providing care, and duration of caregiving.

\section{Care Recipients' Characteristics}

Care recipients' characteristics were measured by functional status, level of physical disability, and cognitive status. The Katz Index of Activities of Daily Living (Katz, Down, Cash, \& Grotz, 1970; Spector, 1990) was used to measure care recipients' functional status. The ADL Index included six items that assessed eating/feeding, bathing, dressing, toilet habits, transferring, and continence, with respondents choosing one response ranging from "not at all difficult" = 1 to "can't do at all" $=3($ alpha $=.92)$. One global item was used to discern the overall level of physical disability. The care recipients' cognitive impairment was measured by an eight-item scale (Kim, 2003). The caregivers provided information about how often the care recipient had difficulty remembering his/her age, finding his/her way around the home, knowing the name of the place where he/she lived, 
recognizing family members, remembering recent events, eating too quickly, bathing, and changing clothes. Higher scores indicate less severe mental impairment. The alpha level for these cognitive variables was .90 .

\section{Mediating Variables}

Mediating variables were measured by three items that provided information about informal social support, formal support and the family's financial adequacy. Informal social support was defined as the number of individuals who would provide the substantial care for care-recipients as a secondary caregiver if the primary caregiver were absent or unavailable. The number of individuals was used to construct an index of social support (Carpenter, 2002). Formal support was assessed by the number of services that family caregivers used during the past six months (Ho, Weitzman, Cui, \& Levkoff, 2000). Formal social services including paid-home care service, day care program, and respite care were counted because these services might provide care to disabled older adults during the daytimes instead of family caregivers. Accordingly, respondents rated their family's financial adequacy for caring for older family members with disabilities. Participants chose one response ranging from " 1 = very inadequate" to " $5=$ very adequate."

\section{The Outcome Variable, Caregivers' Subjective Burden}

The outcome variable, caregivers' subjective burden was assessed by the short Korean version of Family Strain Scale (Morycz, 1985). A total of five items with responses ranging from "not experienced at all," scored as "1," to "experienced a great deal" scored as "4," provided information about the psychological consequences of caregiving, changes in physical health and family functioning resulting from the caregiving situation, changes in one's social and professional life, and the financial burden of caregiving. Higher scores indicated greater caregiver burden. This scale correlates significantly with the Zung Depression Scale (Morycz, 1985), and had acceptable reliability within this study (alpha $=.72)$.

\section{Data Analyses}

The analytic approach of this study involved four stages. First, descriptive statistics characterized the study participants' socio-demographic information, self-rated health, care related information such as care demands, and care recipients' information. Second, the independent-samples $t$-test for two groups and one-way ANOVA for three or more groups were carried out investigating the association between multiple independent variables and the one dependent variable of caregiver burden. Furthermore, if the overall $F$ test was significant, follow-up tests were added to find pair-wise mean differences among groups. 
Third, Pearson correlation coefficients were employed to address the relationship between caregiver burden and continuous variables. Fourth, by analyzing a continuous dependent variable with a combination of categorical and continuous variables presented in the conceptual framework, the hierarchical multiple regression identified significant risk factors (step 1,2,3) and possible mediating factors (step 4,5) that affect the level of caregivers' burden.

\section{RESULTS}

\section{Descriptive and Bivariate Analyses}

Descriptive statistics for the sample and mean differences in sample characteristics and care recipients' characteristics are presented in Table 1. The sample consisted of 1,000 caregivers age 21 or older who were the primary caregivers for disabled older family members. Seventy-eight percent were women $(n=786)$ and $21.4 \%(n=214)$ were men. The male primary caregivers were comprised of spouses $(7.8 \%)$, unmarried sons $(11.5 \%)$, and other relatives $(2.1 \%)$. The mean age was $52.36(S D=14.04)$, with an age range of 20 to 89 years.

Descriptive and bivariate analyses were performed to determine the degree of caregiver burden. Overall, the mean of caregiving burden was $13.94(S D=2.84)$ with a range of 5 to 20. However, there was limited variation among group mean differences. As a result, effect size (Partial Eta Squared) of each group difference was fairly low, ranging from 0.01 to 0.08 .

In analyzing burden within the sample, however, some differences emerge about the experience of caregiving. The mean caregiver burden in female caregivers (14.10) was significantly higher than that of male caregivers (13.31). Analysis of variance determined that burden level differed significantly by age (14.03; $p<.001)$. Based on the Tukey HSD post hoc test of significant difference, caregivers in their twenties (11.73) reported significantly less burden than those in their thirties (13.49), forties (14.06), fifties (14.01), and sixties and over (14.40). The most frequently represented caregivers were daughters-in-law (42.4\%), followed by spouses $(24.0 \%)$, daughters $(16.8 \%)$, sons $(11.5 \%)$, and other relatives $(5.3 \%)$. Differences in caregiving burden were also present based upon the role relationship of caregiver and care recipient $(11.98 ; p<.001)$. A post hoc comparison using the Tukey HSD test was conducted which found that spouses (14.34) and daughters-in-law (14.15) reported significantly higher burden than daughters (13.86) and sons (13.30). Analyses were also conducted on employment and health status of the caregivers. More than $25 \%$ of all respondents were currently employed either full- or part-time. Employed caregivers reported less burden than those who were unemployed $(p<.01)$.

The nature of the caregiving relationship was analyzed by gender, residential arrangement and care recipient diagnoses. Men comprised $30.5 \%$ of the care recipients and women comprised $69.5 \%$. Their average age was $78.09(S D=7.62)$. 
254 / LEE, YOON AND KROPF

Table 1. Sample Demographic Characteristics with Burden Mean Differences $(N=1,000)$

\begin{tabular}{|c|c|c|c|c|}
\hline Variables & Group & $\begin{array}{l}\text { Mean } \\
(S D)\end{array}$ & $\begin{array}{l}\text { Number } \\
(\%)\end{array}$ & $\begin{array}{l}\text { Mean } \\
\text { burden }\end{array}$ \\
\hline \multicolumn{5}{|l|}{ Caregiver Characteristics } \\
\hline \multirow[t]{2}{*}{ Caregiver gender*** } & Male & & $214(21.4 \%)$ & 13.31 \\
\hline & Female & & $786(78.6 \%)$ & 14.10 \\
\hline \multirow[t]{6}{*}{ Caregiver age ${ }^{\star \star \star}$} & $20-29$ & & $33 \quad 3.3 \%)$ & 11.73 \\
\hline & $30-39$ & & $156(15.6 \%)$ & 13.49 \\
\hline & $40-49$ & 52.36 & 302 (30.2\%) & 14.06 \\
\hline & $50-59$ & $(14.04)$ & 197 (1.97\%) & 14.01 \\
\hline & $60-69$ & & $163(16.3 \%)$ & 14.40 \\
\hline & Over 70 & & 149 (14.9\%) & 14.03 \\
\hline \multirow{5}{*}{$\begin{array}{l}\text { Relationship with } \\
\text { care recipient }{ }^{\star \star \star}\end{array}$} & Spouse & & $240(24.0 \%)$ & 14.34 \\
\hline & Son & & 115 (11.5\%) & 13.30 \\
\hline & Daughter-in-law & & 424 (42.4\%) & 14.15 \\
\hline & Daughter & & 168 (16.8\%) & 13.86 \\
\hline & Other relatives & & $53(5.3 \%)$ & 11.98 \\
\hline \multirow[t]{3}{*}{ Employment status ${ }^{\star \star \star}$} & Not working & & 737 (73.7\%) & 14.08 \\
\hline & Full-time & & $113(11.3 \%)$ & 13.83 \\
\hline & Part-time & & $150(15.0 \%)$ & 13.31 \\
\hline \multirow[t]{3}{*}{ 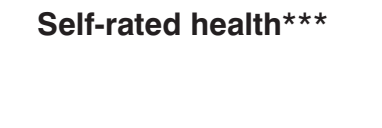 } & Good & & $350(35.0 \%)$ & 13.16 \\
\hline & Fair & & 463 (46.3\%) & 14.16 \\
\hline & Poor & & $187(18.7 \%)$ & 14.83 \\
\hline \multicolumn{5}{|c|}{ Care Recipient Characteristics } \\
\hline \multirow[t]{2}{*}{ Care recipient gender } & Male & & 305 (30.5\%) & 13.98 \\
\hline & Female & & $695(69.5 \%)$ & 13.92 \\
\hline \multirow[t]{4}{*}{ Care recipient age } & $65-69$ & & $162(16.2 \%)$ & 13.94 \\
\hline & $70-74$ & 78.09 & $175(17.5 \%)$ & 13.73 \\
\hline & $75-79$ & (7.62) & $205(20.5 \%)$ & 13.85 \\
\hline & Over 80 & & $458(45.8 \%)$ & 14.05 \\
\hline \multirow[t]{2}{*}{ Co-residence* } & Yes & & $915(91.5 \%)$ & 13.99 \\
\hline & No & & $85(8.5 \%)$ & 13.29 \\
\hline \multirow[t]{3}{*}{ Type of illness $* \star \star$} & Dementia & & $490(49.0 \%)$ & 14.63 \\
\hline & Stroke & & 227 (22.7\%) & 13.85 \\
\hline & Other & & $283(28.3 \%)$ & 12.79 \\
\hline
\end{tabular}

${ }^{\star} p<0.05 .{ }^{* *} p<0.01 .{ }^{* \star} p<0.001$. 
There were no statistically significant differences in caregiver burden based on recipient's gender. More than $90 \%$ of the primary caregivers lived with their care recipient, and co-residing caregivers experienced higher burden than those who did not $(p<.05)$. The results also showed that among the care recipients, $49.0 \%$ suffered from dementia, $22.7 \%$ suffered the effects of a stroke and $28.3 \%$ had the other diseases. In particular, the caregivers who provided care for the elderly with dementia reported greater levels of burden than those caring for persons with other conditions $(p<.001)$.

Table 2 illustrates the distributions of mean scores for measures and correlations with caregiving burden. The mean monthly household income of the sample was $\$ 1714.97(S D=1167.9)$. Overall, the sample spent $59.14(S D=36.71)$ hours in care provision, and the mean duration of caregiving was more than 63 months $(S D=59.17)$. The mean of the ADLs was $9.68(S D=3.38)$. The mean score for cognitive impairments was $3.35(S D=3.02)$ with a range 0 to 8 . Regarding family financial adequacy, the mean was $2.48(S D=.86)$. Accordingly, the mean number of secondary caregivers (informal social support) was $1.15(S D=1.1)$ and $16 \%$ of the respondents used one of the services such as paid home-care, adult day care, and respite care. The family caregivers showed that the average number of used services was $.2(S D=.55)$.

In order to examine the relationship between caregiver burden and continuous variables, Pearson correlation coefficients were computed. The results revealed that caregiving hours (more), ADLs (more severe), cognitive impairments (more severe), financial adequacy (lower), informal support (less) and formal support (greater) were significantly related with higher caregiving burden in the sample.

Table 2. Descriptive Statistics for Measures and Correlations with Caregivers Burden $(N=1,000)$

\begin{tabular}{lccl}
\hline Variables & Mean & $S D$ & Correlation \\
\hline Income (\$) & 1715 & 1167.9 & -.048 \\
Caregiving hours & 59.14 & 36.71 & $.268^{\star \star *}$ \\
Duration of caregiving (mos) & 63.92 & 59.17 & .062 \\
ADLs & 9.68 & 3.38 & $.189^{\star * *}$ \\
Cognitive impairments & 3.55 & 3.02 & $.284^{\star * *}$ \\
Financial adequacy & 2.48 & .86 & $-.150^{* * *}$ \\
Informal support & 1.5 & 1.1 & $-.107^{\star *}$ \\
Formal service & .2 & .55 & $.092^{\star *}$ \\
\hline
\end{tabular}

${ }^{*} p<0.05 .{ }^{* *} p<0.01 .{ }^{* * *} p<0.001$. 


\section{Predictors}

Table 3 presents the results of hierarchical regression analyses that identified significant predictors of caregiving burden based on the conceptual model. Prior to the multiple regression analysis, the explanatory variables were tested to see if they were linearly independent. Generally, if the correlation coefficient is 0.8 or above, multicollinearity may exist (Ahn, Hong, \& Park, 2000). The correlation coefficient level was less than 0.4 , eliminating the risk of multicollinearity and the data analysis plan was implemented to include all variables within the model.

Table 3. Estimates Using Hierarchical Regression $(N=1,000)$

\begin{tabular}{|c|c|c|c|c|c|}
\hline & $\begin{array}{c}\text { Step } 1 \\
\beta\end{array}$ & $\begin{array}{c}\text { Step } 2 \\
\beta\end{array}$ & $\begin{array}{c}\text { Step } 3 \\
\beta\end{array}$ & $\begin{array}{c}\text { Step } 4 \\
\beta\end{array}$ & $\begin{array}{c}\text { Step } 5 \\
\beta\end{array}$ \\
\hline Caregiver age & .058 & -.004 & .040 & .040 & .022 \\
\hline Caregiver gender & $.077^{\star}$ & $.083^{\star}$ & $.099^{* *}$ & $.095^{\star *}$ & $.096^{\star *}$ \\
\hline Relationship with care recipient & $-.081^{* \star}$ & $-.078^{*}$ & -.057 & -.068 & $-.071^{*}$ \\
\hline Caregiver health status & $.195^{\star \star *}$ & $.167^{\star \star *}$ & $.173^{\star \star \star}$ & $.156^{\star \star \star}$ & $.152^{\star \star \star}$ \\
\hline Employment status & -.014 & .028 & .021 & .014 & .014 \\
\hline Income \$ & .006 & .024 & .011 & .055 & .063 \\
\hline Caregiving hours & & $.241^{* * *}$ & $.182^{\star \star \star}$ & $.170 * \star \star$ & $.165^{\star \star \star}$ \\
\hline Duration of caregiving & & .037 & .046 & .040 & .035 \\
\hline Care recipient age & & & $-.104^{\star \star}$ & $-.097^{\star *}$ & $-.092^{\star *}$ \\
\hline Care recipient gender & & & $.062^{\star}$ & .060 & $.063^{*}$ \\
\hline ADLs & & & $.075^{\star}$ & $.070^{*}$ & $.077^{\star}$ \\
\hline Cognitive abilities & & & $-.263^{\star \star *}$ & $-.264^{\star \star \star}$ & $-.259 \star \star \star *$ \\
\hline Financial adequacy & & & & $-.101^{* *}$ & $-.094^{\star *}$ \\
\hline Informal social support & & & & & $-.083^{\star *}$ \\
\hline Formal support & & & & & .051 \\
\hline$F$ & $11.221^{* \star *}$ & $15.809 * * *$ & $19.644^{\star * *}$ & $18.865^{\star * *}$ & $17.174^{\star \star *}$ \\
\hline$R$ square & .063 & .113 & .193 & .199 & .207 \\
\hline Adjusted $R$ square & .058 & .106 & .183 & .189 & .195 \\
\hline$R$ square change & $.063^{\star \star \star}$ & $.050 * \star \star$ & $.080 * \star \star$ & $.005^{\star *}$ & $.006^{\star \star}$ \\
\hline
\end{tabular}

Note: Dummy variables codes: Caregiver gender (Male $=0$, Female $=1$ ), Care recipient gender $($ Male $=0$, Female $=1)$, Relationship with care recipient (Daughter-in-law $=0$, Others $=1$ ).

${ }^{*} p<0.05 .{ }^{* *} p<0.01 .{ }^{* *} p<0.001$. 
Step 1 analyzed the relationship between the caregiver's characteristics and the degree of caregiver burden $(F=11.221, p<.001)$. These characteristics explained $5.8 \%$ of the dependent variable. When the care provider was a daughter-in-law $(\beta=-.081, p<.05)$ and was female $(\beta=.077, p<.05)$, the level of caregiver burden increased. The degree of caregiver burden was more likely to increase as the degree of the self-rated health status decreased $(\beta=.195, p<.001)$. Caregiver age, employment status, and monthly household income were not significant predictors in this model.

Step 2 tested the actual level of caregiving involvement such as hours per week devoted to caregiving, and the overall duration of caregiving on burden $(F=15.809, p<.001)$. This step explained approximately $10.6 \%$ of the variance, and the $R$ square value also significantly increased $(p<.001)$. Caregiver gender $(\beta=.083, p<.05)$, relationship with care recipient $(\beta=-.078, p<.05)$, and health status $(\beta=.167, p<.001)$ remained within the model as significant predictors of caregiver burden. A greater number of hours in caregiving per week $(\beta=.241, p<.001)$ was an additional predictor of higher caregiver burden.

Step 3 added descriptive data about the care recipient $(F=19.644, p<.001)$. The $R$ square $(.183)$ significantly increased $(p<.001)$. The findings showed that caregiver gender $(\beta=.099, p<.01)$, caregiver health status $(\beta=.173, p<.001)$, weekly caregiving hours $(\beta=.182, p<.001)$, caregiver recipient age $(\beta=-.104$, $p<.01)$, care recipient gender $(\beta=.062, p<.05)$, ADLs $(\beta=.075, p<.05)$, and care recipient's cognitive ability $(\beta=-.263, p<.001)$ were significantly associated with caregiver burden. Caregivers who provided care to female older adults reported higher burden than those caring for older men. There was a positive correlation between impairment and burden. As the level of the recipient's physical and/or cognitive disabilities increased, the greater the caregiver's reported burden. Interestingly, the age of the care recipient was negatively correlated with the level of burden.

In the next analyses (Step $4 \& 5$ ), two mediating variables were added to the model. Step 4 included the caregiver's financial capacity to provide adequate care $(F=18.865, p<.001)$. The results showed an increase in the $R$ square (.189) which was statistically significant $(p<.05)$. Less burden was reported by caregivers who had adequate financial resources $(\beta=-.101, p<.01)$. Step 5 utilized all predictors for caregiver burden, adding informal social support and formal social support $(F=17.174, p<.001)$. The $R$ square $(.195)$ increased and this change was statistically significant $(p<.05)$. Caregiver gender $(\beta=.096, p<.01)$, relationship with care recipient $(\beta=-.071, p<.05)$, caregiver health status $(\beta=.152, p<.001)$, hours of care per week devoted to caregiving $(\beta=.165$, $p<.001)$, the care recipient's age $(\beta=-.092, p<.01)$, gender $(\beta=.063, p<.05)$, ADLs $(\beta=.077, p<.05)$, cognitive impairment $(\beta=-.259, \mathrm{p}<.001)$, the caregiver's financial status $(\beta=-.094, p<.01)$, and informal social support $(\beta=-.083$, $p<.001)$ were significantly associated with the degree of caregiver burden. In particular, as the number of persons who provided aid to the caregivers increased, their degree of burden decreased. 


\section{DISCUSSION}

This study depicts the current status of family caregiving in South Korea based upon a conceptual model that included caregiver and care recipient factors, the nature of the caregiving relationship, and resources available to decrease the stresses of care provision. The data indicated that $95 \%$ of the primary caregivers reside with the care recipient which supports the concept of intergenerational families within South Korea. Males comprised about one-fifth of the caregivers, with unmarried sons representing the highest proportion (11.5\%) of men. This gender distribution represents a similar gender ratio to western families where $75 \%-80 \%$ of care provision is assumed by women (Health \& Human Services, 1998; National Alliance for Caregiving and AARP, 1997). However, findings of the current study diverge from the caregiving hierarchy found in American families, where spouses and daughters assume primary caregiving roles. In Korean families, daughters-in-law were the most typical caregivers, comprising $42.4 \%$ of the sample. This pattern indicates that South Korean caregiving is non-consanguineous which appears to add to the sense of burden of caregivers within this cultural context.

Consistent with previous research, this study also identified several significant predictors of higher caregiving burden. Higher levels of caregiver burden are associated with daughters-in-law who receive little informal support and assume greater amounts of weekly caregiving hours, specifically while caring for older females. Similar to other research (e.g., Mui, 1992) the present study demonstrated the importance of the care recipient's gender in relation to burden. This study also confirmed that caregiver burden is affected by the degree of the care recipient's dependency in tasks of daily life as well as by the degree of cognitive impairment (e.g., Franks \& Stephens, 1996; Monahan \& Hooker, 1995; Stull et al., 1994; Yoon, 2003). Accordingly, financial adequacy and informal social support were significantly tested to lessen the intensity of caregiver burden (e.g., Choi, 1993; Miller et al., 2001).

The results also did yield some unexpected findings within the sample. For example, caring for older family members did not increase the perceived burden in care providers, as caregivers for younger recipients reported higher burden. One possible explanation is the time horizon that care providers construct about the length of the caregiving role. Caregivers might perceive that younger care recipients will require a longer time frame of care, which leaves the care provider feeling "trapped" within the role. This explanation may be especially true for daughters-in-law, who struggle with the interpersonal dynamics of caring for their husband's parent. A rival explanation may be founded upon expectations of who should receive care. Caregivers may be unwilling to accept the fact that relatively younger elderly had severe physical and/or mental impairment that required assistance. Additionally, the data showed formal social support did not buffer the level of caregiving burden. Family caregivers who used social and/or medical 
services in this sample generally were already in extremely demanding caregiving situation due to patients' severe disabilities, which could meet the eligibility condition for long-term care services in South Korea.

\section{Limitations of this Study and Implications for Future Research}

Although this study makes crucial contributions to empirical caregiving research in South Korea, a few of limitations should be addressed. First, the results of this study are not generalized to all Koreans in that this research employs purposive sampling and the participants are limited to Seoul residents. Seoul is the most modernized South Korean city where social services are more readily available, as compared to other regional or rural areas. In addition, almost $50 \%$ of the sample was older adults who had previously used or were currently using social and/or medical services due to their impairments. As a result, the findings might have some limitation in generalizing to the disabled older adults who did not use any formal services or who live in more rural areas of the country. Given the non-probability nature of the sample, the use of statistical significance tests in this manuscript is for illustrative purposes only. Future research employing a nationally representative sample would allow generalization from the results of this study. Secondly, a cross-sectional design was employed and so the data did not provide an opportunity to determine changes in burden over time. A longitudinal design could test the determinants of caregiving burden according to changing conditions in demographic characteristics of both caregivers and care recipients. Qualitative studies are also necessary to explore deeper profiles in caregiving within the South Korean context.

In summary, the present study has contributed to the caregiving literature by examining eldercare in South Korea. Based upon a conceptual model of stresses and resources, burden was explained by a combination of caregiver and care recipient characteristics, as well as resources available to assist with eldercare. Some unique caregiving qualities were identified within the South Korean families, such as daughters-in-law being the primary family caregivers. The highest rates of burden were found in the situation where daughters-in-law were caring for a woman with dementia in the absence of informal support. Taken as a whole, these findings provide support for viewing caregiving in Korean families somewhat differently than in the dominate western family.

\section{REFERENCES}

Ahn, C. H., Hong, S. P., \& Park, Y. K. (2000). Introduction of econometrics. Seoul: Jinyoungsa.

Aneshensel, C. S., Pearlin, L. I., Mullan, J. T., Zarit, S. H., \& Whitlach, C. J. (1995). Profiles in caregiving: The unexpected career. San Diego, CA: Academic Press. 
Barusch, A. S., \& Spaid, W. M. (1989). Gender differences in caregiving: Why do wives report greater burden? The Gerontologist, 29, 667-676.

Biegel, D. E., \& Schulz, R. (1999). Caregiving and caregiver interventions in aging and mental illness. Family Relations, 48, 345-354.

Bullock, K., Crawford, S. L., \& Tennstedt, S. L. (2003). Employment and caregiving: Exploration of African American caregivers. Social Work, 48, 150-162.

Burns, A., \& Rabins, P. (2000). Carer burden in dementia. International Journal of Geriatric Psychiatry, 15, S9-13.

Call, K. T., Finch, M. A., Huck, S. M., \& Kane, R. A. (1999). Caregiver burden from a social exchange perspective: Caring for older people after hospital discharge. Journal of Marriage and the Family, 61, 688-699.

Cantor, M. H. (1983). Strain among caregivers: A study of experience in the United States. The Gerontologist, 23, 597-604.

Carpenter, B. D. (2002). Family, peer, and staff social support in nursing home patients: Contributions to psychological well-being. The Journal of Applied Gerontology, 21, 275-293.

Chee, Y. K. (2000). Elder care in Korea: The future is now. Aging International, 26, 25-37.

Chee, Y. K., \& Levkoff, S. E. (2001). Culture and dementia: Accounts by family caregivers and health professionals for dementia-affected elders in South Korea. Journal of Cross-Cultural Gerontology, 16, 111-125.

Choi, H. K. (1993). Cultural and non-cultural factors as determinants of caregiver burden for the impaired elderly in South Korea. The Gerontologist, 33, 8-15.

Clipp, E. C., \& George, L. K. (1990). Caregiver needs and patterns of social support. Journal of Gerontology, 45, S102-111.

Franks, M. M., \& Stephens, M. A. P. (1996). Social support in the context of caregiving: Husbands' provision of support to wives involved in parent care. Journal of Gerontology, 51B, 43-52.

Hannappel, M., Calsyn, R. J, \& Allen, G. (1993). Does social support alleviate the depression of caregivers of dementia patients? Journal of Gerontological Social Work, $20,35-51$.

Health and Human Services. (1998). Informal caregiving: Compassion in action. Washington, DC: Department of Health and Human Services.

Ho, C. J., Weitzman, P. F., Cui, X., \& Levkoff, S. E. (2000). Stress and service use among minority caregivers to elders with dementia. Journal of Gerontological Social Work, $33,67-88$.

Huang, H. L., Shyu, Y. L., Chen, M. C., Chen, S. T., \& Lin, L. C. (2003). A pilot study on a home-based caregiver training program for improving caregiver self-efficacy and decreasing the behavior problems of elders with dementia in Taiwan. International Journal of Geriatric Psychiatry, 18, 337-345.

Hughes, S. L., Giobbie-Hurder, A., Weaver, F. M., Kubal, J. D., \& Henderson, W. (1999). Relationship between caregiver burden and health-related quality of life. The Gerontologist, 39, 534-545.

Katz, S., Down, T., Cash, H., \& Grotz, R. (1970). Progressive development of the Index of ADL. The Gerontologist, 10, 20-30.

Kim, J. M., Shin, I. S., Jeong, S. J., Gormley, N., \& Yoon, J. S. (2002). Predictors of institutionalization in patients with dementia in Korea. International Journal of Geriatric Psychiatry, 17, 101-106. 
Kim, J-S. (2001). Daughters-in-law in Korean caregiving families. Journal of Advanced Nursing, 36, 399-408.

Kim, J-S., \& Lee, E-H. (2003). Cultural and noncultural predictors of health outcomes in Korean daughter and daughter-in-law caregivers. Public Health Nursing, 20, 111-119.

Kim, K. H. (2003). Comprehensive study for the elderly welfare policy in Seoul: Survey and policy recommendations. Seoul Development Institute.

Knight, B. G., Robinson, G. S., Flynn Longmire, C. V., Chun, M., Nakao, K., \& Kim, J. H. (2002). Cross cultural issues in caregiving for persons with dementia: Do familism values reduce burden and distress? Aging International, 27, 70-94.

Korean Institute for Health and Social Affairs (KIHASA). (1998). Living state and its policy implications of the Korean elderly.

Korean Institute for Health and Social Affairs (KIHASA). (2001). National survey of long term care services needs for elderly persons.

Korea National Statistical Office (KNSO). (2000a). Population projections. Retrieved October 1, 2005 from: www.nso.go.kr.

Korea National Statistical Office (KNSO). (2000b). Population and housing census. Retrieved September 5, 2005 from: www.nso.go.kr.

Kramer, B. J., \& Kipnis, S. (1995). Eldercare and work-role conflict: Toward an understanding of gender differences in caregiving burden. The Gerontologist, 35, 340-348.

Lee, H. (2002). Experience of caregiving daughters-in-law in South Korea. Unpublished doctoral dissertation, University of Georgia.

Levande, D. I., Herrick, J. M., \& Sung, K. T. (2000). Eldercare in the United States and South Korea. Journal of Family Issues, 21, 632-651.

Miller, B., \& Guo, S. (2000). Social support for spouse caregivers of persons with dementia. Journal of Gerontology, 55B, S163-172.

Miller, B., Townsend, A., Carpenter, E., Montgomery, R. V. J., Stull, D., \& Young, R. F. (2001). Social support and caregiver distress: A replication analysis. Journal of Gerontology, 56B, S249-256.

Monahan, D. J., \& Hooker, K. (1995). Health of spouse caregivers of dementia patients: The role of personality and social support. Social Work, 40, 305-314.

Morycz, R. K. (1985). Caregiving strain and the desire to institutionalize family members with Alzheimer's disease: Possible predictors and model development. Research on Aging, 7, 329-361.

Mui, A. C. (1992). Caregiver strain among black and white daughter caregivers: A role theory perspective. The Gerontologist, 32, 203-212.

National Alliance for Caregiving and AARP. (1997). Family caregiving in the U.S.: Findings from a national survey. Bethesda, MD: National Alliance for Caregiving; and Washington, DC: AARP.

Neal, M. B., Chapman, N. J., Ingersol-Dayton, B., \& Emlen, A. C. (1993). Balancing work and caregiving for children, adults, and elders. Thousand Oaks, CA: Sage Publications.

Ory, M. G., Hoffman, R. R., Yee, J. L., Tennstedt, S., \& Schulz, R. (1999). Prevalence and impact of caregiving: A detailed comparison between dementia and nondementia caregivers. The Gerontologist, 39, 177-188.

Pearlin, L., Mullan, J., Semple, S., \& Skaff, M. (1990). Caregiving and the stress process: An overview of concepts and their measures. The Gerontologist, 30, 583-594. 
Pratt, C. C., Schmall, V. L., Wright, S., \& Cleland, M. (1985). Burden and coping strategies of caregivers to Alzheimer's patients. Family Relations, 4, 27-33.

Spector, W. D. (1990). Functional disability scales. In R. Spilker (Ed.), Quality of life assessments in clinical trials (pp. 115-129). New York: Raven Press.

Stull, D. E., Kosloski, K., \& Kercher, K. (1994). Caregiver burden and generic well-being: Opposite sides of the same coin? The Gerontologist, 34, 88-94.

Sung, K. T. (1991). Family-centered informal support networks of Korean elderly: The resistance of cultural traditions. Journal of Cross-Cultural Gerontology, 6, 431-447.

Thomas, P., Chantoin-Merlet, S., Hazif-Thomas, C., Belmin, J., Montagne, B., Clement, J. P., Lebruchec, M., \& Billon, R. (2002). Complaints of informal caregivers providing home care for dementia patients: The pixel study. International Journal of Geriatric Psychiatry, 17, 1034-1047.

Yoon, H. (2003). Factors associated with family caregivers' burden and depression in Korea. International Journal of Aging and Human Development, 57, 291-311.

Youn, G., \& Song, D. (1992). Aging Korean's perceived conflicts in relationships with their offspring as a function of age, gender, cohabitation status, and marital status. Journal of Social Psychology, 132, 299-305.

Zarit, S. H., Reever, K. E., \& Bach, S. (1980). Relatives of the impaired elderly: Correlates of feeling of burden. The Gerontologist, 20, 649-655.

Zarit, S. H., Todd, P. A., \& Zarit, J. M. (1986). Subjective burden of husbands and wives as caregivers: A longitudinal study. The Gerontologist, 26, 260-266.

Direct reprint requests to:

Minhong Lee

Department of Social Welfare

Dong-Eui University

995 Eomgwangno Busan-Jin-Gu

Busan 614-714

South Korea

e-mail: minhong@deu.ac.kr 
Copyright of International Journal of Aging \& Human Development is the property of Baywood Publishing Company. Inc. and its content may not be copied or emailed to multiple sites or posted to a listserv without the copyright holder's express written permission. However, users may print. download, or email articles for individual use. 